\title{
Comunicação de conhecimentos nas aulas de Matemática a partir de jogos de linguagem
}

\author{
Michele Regiane Dias Veronez ${ }^{1}$ \\ Jackson Rodrigo Soares ${ }^{2}$
}

\section{RESUMO}

No ambiente de uma sala de aula de matemática, professores e alunos se deparam com a necessidade de estabelecer uma comunicação, visando à criação de um espaço no qual se possa discutir sobre conceitos matemáticos de forma a favorecer a ocorrência de significação desses conceitos. Porém, a linguagem utilizada pelos sujeitos presentes na aula é diversificada. Daí a possibilidade de tais linguagens serem analisadas. Alicerçados nos pressupostos teóricos do filósofo Ludwig Wittgenstein, apresentamos, neste trabalho, uma interpretação dos jogos de linguagem e das semelhanças de família entre esses jogos, a partir das linguagens utilizadas por alunos e professor em um ambiente de Modelagem Matemática. Na análise constatamos que os alunos se utilizam do jogo de linguagem da língua materna para comunicar ideias matemáticas e que suas enunciações ganham significado no jogo de linguagem da matemática por guardarem semelhanças de família entre elas.

PALAVRAS-CHAVE: Linguagens. Jogos de Linguagem. Semelhanças de Família. Modelagem Matemática.

Communication of Knowledge in Mathematics Classes from Language Games

\begin{abstract}
In the environment of a Mathematics classroom, teachers and students are faced with the need to establish communication, aiming at creating a
\end{abstract}

${ }^{1}$ Doutora em Ensino de Ciências e Educação Matemática. Universidade Estadual do Paraná Campus de União da Vitória, União da Vitória, Paraná, Brasil. E-mail. miredias@gmail.com

${ }^{2}$ Graduação - Licenciatura em Matemática.Universidade Estadual do Paraná - Campus de União da Vitória, União da Vitória, Paraná, Brasil. E-mail: jacksonrodrigosoares@gmail.com 
space in which to discuss mathematical concepts in order to support the occurrence of meaning of these concepts. However, the language used by the subjects present in the class is diverse. Hence the possibility of such languages being analyzed. Based on the theoretical assumptions of the philosopher Ludwig Wittgenstein, we present, in this work, an interpretation of language games and family resemblances between these games, from the languages used by the students and the teacher in a Mathematical Modeling environment. In the analysis we verified that students use the language game of the mother language to communicate mathematical ideas and that their enunciations gain meaning in the language game of mathematics because they have family resemblances between them.

KEYWORDS: Languages. Language Games. Family Resemblances. Mathematical Modeling.

\section{Introdução}

Em um ambiente de sala de aula a comunicação entre professores e alunos se faz indispensável. Nesse sentido, os discursos produzidos durante as aulas precisam ser compreendidos, bem como a linguagem, ou melhor dizendo, as linguagens que os ancoram. Tais linguagens, para além de atender a necessidade de comunicar conceitos, precisam ser compreendidas pelos alunos e professor.

Estudos $^{3}$ sobre os pressupostos teóricos de Ludwig Wittgenstein, filósofo austríaco que viveu no século XIX originaram o presente trabalho que, se subsidia na sua obra intitulada Investigações Filosóficas, a qual trata a linguagem a partir dos usos que fazemos dela. Ao discutir sobre os modos de conceber a linguagem, nessa obra, esse renomado filósofo contemporâneo traz terminologias como jogos de linguagem e semelhanças

\footnotetext{
3 Esse artigo foi realizado no âmbito de um projeto de pesquisa, vinculado à Fundação Araucária (Apoio ao Desenvolvimento Científico e Tecnológico do Paraná), intitulado: A linguagem no contexto escolar escolar e seus usos: implicações para a aprendizagem em Matemática.
} 
de família e os denota como atividades que estão entrelaçadas ao uso da linguagem e a sua totalidade.

O desenvolvimento deste estudo tem como foco a seguinte questão: quais linguagens se apresentam nos discursos de alunos e professor em um ambiente de Modelagem Matemática? Na busca por uma resposta a tal questão, primeiramente, identificamos os jogos de linguagem manifestos nas interações entre alunos do quarto ano de um curso de licenciatura em Matemática, na disciplina de Introdução à Modelagem Matemática, e na interação deles com a professora da referida disciplina. Em momento posterior, analisamos tais jogos na tentativa de reconhecer semelhanças de família entre eles.

Trazemos nas seções subsequentes considerações acerca da linguagem sob a perspectiva de Ludwig Wittgenstein, aspectos da Modelagem Matemática na Educação Matemática, o cenário investigado e nossas opções metodológicas. Em seguida, discutimos duas atividades de modelagem matemática, evidenciando nossas intrepetações e reflexões com base no aporte teórico adotado. Por fim, tecemos considerações sobre a investigação realizada.

\section{A perspectiva wittgensteiniana de linguagem}

O pensamento de Ludwig Wittgenstein contém duas fases distintas marcadas pelas obras: Tractatus Logico-Philosophicos que se constitui em uma fase na qual a pergunta orientadora era: qual a essência da linguagem?, e a obra Investigações Filosóficas, reconhecida como a segunda fase do pensamento wittgensteiniano, que considera o modo como a linguagem funciona, nos usos que fazemos dela.

Nessa segunda fase, aporte teórico desse trabalho, Wittgenstein (2012), nos diz que não há uma linguagem, mas linguagens, ou seja, diversos usos da linguagem. Condé (1998), acrescenta que para esse filósofo a linguagem, 
estando diretamente associada ao uso que fazemos dela, pode ganhar significados diferentes de acordo com o contexto no qual ela aparece.

Assumir a linguagem como constitutiva do contexto, nas palavras de Vilela e Mendes (2011, p. 8), significa olhar para a linguagem "em termos de atividade, como constitutiva das coisas, e não como meramente 'descritiva' delas", assim, se faz adequado falarmos de linguagens.

$\mathrm{Na}$ pluralidade do uso da linguagem e das regras que regem os diferentes discursos, o que faz ou não sentido no uso da linguagem obedece às regras que compõem a gramática.

A gramática, nesse contexto, não tem seu significado usual. Ela comporta as regras e a estrutura da linguagem e, assim, indica como podem ser usadas as expressões em diferentes contextos. Indica as regras de uso das palavras, o que faz sentido e o que é certo ou errado (VILELA; MENDES, 2011, p. 13).

Na obra Investigações Filosóficas, Wittgenstein denomina os diversos usos da linguagem, cada qual inserido em um contexto, de jogos de linguagem,

podemos imaginar também que todo o processo de uso de palavras [...] seja um dos jogos por meio dos quais as crianças aprendem sua língua materna. Quero chamar esses jogos de "jogos de linguagem" [...]. Chamarei de "jogos de linguagem" também a totalidade formada pela linguagem e pelas atividades com as quais ela vem entrelaçada (WITTGENSTEIN, 2012, p. 18 e 19).

Nessa perspectiva são os jogos de linguagem que definem as linguagens que cada indivíduo emprega durante as diversas funções que realiza na interação com o meio em que vive. Tais linguagens têm papéis diferentes, se modificam/alteram e ganham diferentes significados de acordo com o contexto em que elas são usadas. Para Wittgenstein (2012), os jogos de 
linguagem fazem parte da vivência das pessoas e se baseiam e se sustentam no que ele chama de formas de vida 4 . Esse autor acrescenta que o "para uma grande classe de casos - mesmo que não para todos - de utilização da palavra "significado", pode-se explicar esta palavra do seguinte modo: O significado de uma palavra é o seu uso na linguagem" (WITTGENSTEIN, 2012, p. 38).

O exemplo proposto por Vilela e Mendes (2011) em relação à palavra "triângulo" elucida que seu significado depende do contexto em que ocorre, isto é, podemos falar em 'triângulo amoroso' ou da figura geométrica, ambos pertinentes em nossa gramática e não associados necessariamente ao mesmo referente. Ou seja, podemos falar em triângulo em um jogo de linguagem (jogo de linguagem da matemática), pertinente a nossa gramática, como sendo uma figura geométrica de três lados e, em outro jogo de linguagem (jogo de linguagem do cotidiano), a palavra triângulo, pode sugerir a expressão triângulo amoroso e remeter à relação amorosa entre três pessoas, considerando outras regras gramaticais estabelecidas.

Veronez e Estevam (2015), ampliam os contextos nos quais a palavra triângulo pode ser empregada ao exemplicar que "triângulo, no trânsito em rodovias, sinaliza a ocorrência de panes (pneu furado, problemas elétricos, entre outros) em veículos que nelas trafegam; na música, refere-se a um instrumento metálico com determinado timbre” (p. 308). Ao elucidar esses diferentes usos e significados da palavra triângulo ressaltam que " todos esses usos são pertinentes e, de fato, existem, mas, em cada situação, a palavra triângulo assume um significado distinto" (VERONEZ; ESTEVAM, 2015, p. 308).

Assim, os significados das palavras são produzidos pelo sujeito imerso em jogos de linguagem; mudando os contextos, mudam-se também os significados das palavras. Desta forma, os significados estão atrelados ao modo como as palavras são usadas e ao contexto em que elas emergem.

\footnotetext{
${ }^{4}$ Ludwig Wittgenstein utiliza a expressão 'forma de vida' associada aos hábitos, costumes e
} ações que fundamentam as atividades em geral, realizadas pelo sujeito. 
Como nos diz Wittgenstein (2012, p.18), "na prática do uso da linguagem, uma parte grita as palavras, a outra age de acordo com elas".

Ao retomar os significados que podem vir atrelados à palavra triângulo cabe ressaltar que, nos mesmos contextos sugeridos, ela ainda pode ganhar significados distintos. Por exemplo, no trânsito também é possível associar triângulo à placa preferencial. Logo, é na variação dos usos das palavras e das manifestações linguísticas em cada forma de vida, em cada jogo de linguagem, e alicerçadas nas regras gramaticais que aquele contexto impõe, que ocorre a atribuição de significado.

O que permite associar diferentes usos a uma mesma palavra são as amarras que podem ser estabelecidas entre os diversos significados atribuídos a ela. Tais significações, conforme assinalado por Wittgenstein (2012), compõem uma complexa rede de semelhanças, a qual o próprio autor convencionou chamar 'semelhanças de família'.

Para elucidar a caracterização de semelhança de família

olhe, por exemplo, os jogos de tabuleiro, com seus variados parentescos. Passe agora para os jogos de cartas: aqui você encontra muitas correspondências com aquela primeira classe, mas muitos traços comuns desaparecem, outros se apresentam. Se passarmos agora para os jogos de bola, veremos que certas coisas comuns são mantidas, ao passo que muitas se perdem. - Prestamse todos eles ao "entretenimento"? Compare o xadrez com o ludo. Ou há, por toda parte, ganhar e perder, ou uma concorrência dos jogadores? Pense nas paciências. Nos jogos de bola há ganhar e perder; mas, se uma criança atira a bola contra a parede e a agarra novamente, neste caso este traço desapareceu. Veja que papel desempenham habilidade e sorte. E quão diferente é habilidade no jogo de xadrez e habilidade no jogo de tênis. Pense agora nas brincadeiras de roda: aqui se encontra o elemento entretenimento, mas quantos dos outros traços característicos desapareceram! (WITTGENSTEIN, 2012, p. 51-52). 
As semelhanças de família são, portanto, parentescos que podem se fazer presentes nos jogos de linguagem - intrajogo ou entre jogos -, não necessariamente, porém, em todos eles. Veiga-Neto e Lopes (2007), afirmam que as semelhanças de família não pressupõem os mesmos atributos em todos os elementos. Apenas a existência de alguns atributos comuns a dois ou mais elementos pode garantir semelhanças de família entre eles.

Como temos interesse em identificar jogos de linguagem e semelhanças de família nas linguagens dos alunos em ambiente de modelagem matemática, discorremos a seguir sobre Modelagem Matemática na Educação Matemática.

\section{Modelagem Matemática na Educação Matemática}

Embora existam diversas concepções e elas pareçam se distanciar no modo como são descritas pelos pesquisadores da área, a Modelagem Matemática está, de modo geral, relacionada com o tratamento de problemas oriundos de situações da realidade, por meio da matemática.

Adotamos, neste estudo, que a Modelagem Matemática consiste na busca por uma solução para um problema, que pode ser sugerido pelos alunos ou pelo professor; um conjunto de procedimentos, que viabiliza o envolvimento com estruturas e conceitos matemáticos e uma análise consciente da resposta obtida para tal problema, podendo essa ser reconhecida, ou não, como solução. Sendo assim, conforme salientam Almeida e Dias (2007), para o desenvolvimento de uma atividade de modelagem é necessário que haja compreensão de uma situação-problema, a partir da organização de informações referentes a ela, para a seguir, levantar hipóteses e procurar analisá-las. Também é preciso definir as variáveis envolvidas, cujas relações conduzem à solução do problema. Por fim, se faz necessário avaliar e julgar as respostas obtidas. 
Com relação à importância da análise dos resultados e da análise das resoluções, Veronez (2013, p.29) enfatiza que

é importante que os alunos comuniquem os resultados da atividade de modelagem aceitos pelo grupo como resposta para o problema. É nessa comunicação que os alunos têm oportunidade de argumentar acerca dos encaminhamentos assumidos por eles na obtenção de tais resultados, além de se configurar em um espaço para os alunos se convencerem e convencerem aos demais alunos da sala e ao professor de que a solução obtida é consistente em relação aos conceitos matemáticos utilizados e à situação em estudo.

Desta forma, um aspecto importante a ser considerado em atividades de modelagem matemática é o contexto em que se realizam (ALMEIDA, TORTOLA, 2014), já que ele determina as linguagens suscitadas pelos alunos e pelo professor, quando buscam encontrar uma solução para o problema que origina a atividade de modelagem matemática.

Essas linguagens se fundamentam nos usos que eles fazem das palavras e subsidiam as escolhas adotadas, assim como as formas de representação por eles usadas. Logo, diferentes representações podem ser evocadas e diferentes jogos de linguagem podem emergir no contexto de aulas que concentram atividades de modelagem matemática. Assim, o desenvolvimento de uma atividade de modelagem matemática proporciona a utilização de linguagens diversas. Olhar para essas linguagens nos leva a fazer escolhas, que seguem descritas na próxima seção. 


\section{O cenário investigado e as opções metodológicas}

A interpretação ora apresentada foi realizada à luz dos jogos de linguagem presentes nos discursos orais dos alunos 5 do quarto ano do curso de Licenciatura em Matemática enquanto interagiam no desenvolvimento de atividades de modelagem matemática no contexto da disciplina de Introdução à Modelagem Matemática.

As duas atividades de modelagem analisadas, foram apresentadas e discutidas, cada uma, por um grupo de alunos da turma. Cabe destacar que tais atividades se encontram em artigos científicos e que, faz parte da dinâmica da disciplina os alunos estudarem e conduzirem o debate de alguns artigos que abordam atividades de modelagem matemática.

Os episódios ${ }^{6}$ que subsidiaram nossas interpretações e que aparecem descritos são recortes das transcrições dos áudios gravados durante as aulas. Nem sempre os episódios apresentados seguem a ordem cronológica do momento da aula, contudo, foram assim organizados por conterem informações consideradas relevantes no processo de análise. Como forma de explicitar o diálogo dos grupos usamos nos episódios a designação A21 para se referir ao aluno 2 do grupo 1, da mesma forma, A13 refere-se ao aluno 1 do grupo 3. Quando nos referimos aos alunos responsáveis por apresentar a atividade de modelagem matemática utilizamos a letra $\mathrm{S}$ e para a professora da disciplina, que sempre participou das discussões orientadas pelos alunos apresentadores, usamos a letra $\mathrm{P}$.

\footnotetext{
5 Os alunos foram consultados se tinham interesse em participar da coleta de dados, e para isso, assinaram um Termo de Compromisso Livre e Esclarecido (TCLE) autorizando o uso de suas falas e anotações produzidas durante a aula.

6 Os episódios correspondem a trechos dos diálogos ocorridos durante as aulas, as quais foram gravadas. Tais diálogos, por serem muito longos, foram fragmentados no que denominamos episódios, com vistas a explicitar a análise que realizamos.
} 


\section{Uma interpretação acerca dos dados coletados}

Nessa seção, intencionando discutir sobre as linguagens manifestas no desenvolvimento de duas atividades de modelagem, trazemos alguns episódios, segundo os quais identificamos diferentes usos da linguagem e sob os quais fazemos uma interpretação, pautados no referencial teórico adotado.

Para discussão da atividade de modelagem matemática intitulada Energia Elétrica, os alunos apresentadores disponibilizaram um material7 que sugeria um estudo da lei de formação e comportamento da função afim a partir do seguinte questionamento: de que forma o valor a ser pago pelo consumo de energia é calculado? Além disso, esse material solicitava que fosse realizado um estudo da função afim com relação às características desse tipo de função (domínio, contradomínio e imagem, crescimento e decrescimento) e da análise da representação gráfica dessa função.

A questão que originou o desenvolvimento dessa atividade tinha como foco a representação algébrica e gráfica do custo do uso da energia elétrica em um mês qualquer. Assim, os acadêmicos que conduziram a atividade assumiram o valor de $\mathrm{R} \$ 0,72$ como sendo o valor de um quilowatt/hora, informação que se fez necessária na resolução da atividade e que não era trazida no material disponibilizado.

\section{Episódio 1}

A11: como calcular o valor a ser pago em reais em uma conta de energia elétrica? A21: consumo de energia em quilowatt multiplicado pelo valor do quilowatt... A11: consumo de energia em quilowatts por hora multiplicado pelo valor do quilowatt hora...

A21: a energia que você gastou no mês vezes (...)

\footnotetext{
7 Este material pode ser encontrado no artigo de TORTOLA, E.; REZENDE, V. Analisando a conta de energia elétrica: o estudo de função afim por meio de uma sequência de atividades. In: IV EPMEM - Encontro Paranaense de Modelagem em Educação Matemática. Maringá - PR, 2010.
} 
A11: expresse a função que você obteve para representar o valor pago em reais para calcular o consumo em quilowatt...

A21:0,72 vezes....

A11: o consumo de energia...

A21: o consumo de energia, daí a gente pode atribuir um valor, então vamos colocar $o$ vezes $0,72 \ldots 0,72$ vezes $x$.

A11: quando x é igual ao valor do consumo de energia....

No Episódio 1 notamos que os alunos utilizam o jogo de linguagem da língua materna ao tentar procurar uma relação entre o consumo e o preço do quilowatt/hora e quando se referem à relação que determina o custo para um valor de quilowatt/hora qualquer. Neste episódio identificamos semelhanças de família da linguagem natural com o jogo de linguagem da matemática quando os alunos procuram uma representação algébrica para o consumo de energia e se referem a esse consumo tanto na linguagem natural quanto matematicamente, porém nessa última utilizam a variável x.

A discussão que denota a procura por encontrar um valor para o consumo de energia é composta por termos da linguagem natural como "atribuir", "colocar o vezes" que fazem referência a conceitos matemáticos e, ao mesmo tempo, expõem uma ideia por meio da linguagem natural. Como os alunos que fazem parte do diálogo conhecem as regras do jogo de linguagem que ali ocorre, as semelhanças de família entre o jogo de linguagem da matemática e da linguagem natural garantem que os termos que compõem tal diálogo sejam entendidos entre esses alunos.

$\mathrm{Na}$ discussão da atividade, quando solicitado uma representação para o domínio, contradomínio e imagem da função, os alunos recorreram ao uso de palavras externas ao contexto matemático como ilustrado no Episódio 2.

\section{Episódio 2}

A11: isso? Então, qual é o domínio, contradomínio e imagem dessa função? Especifique quais os conjuntos numéricos...domínio.... Domínio é esse aqui? É daqui que leva para lá... 
A21: então vai ser os números...

A11: naturais?

A21: é, ou os inteiros não sei...

A11: mas eu posso consumir energia quebrada né, então os reais...

A21: a imagem também são os reais né, positivos...

A utilização da palavra "quebrada" representa uma semelhança de família do jogo de linguagem da matemática com o jogo de linguagem da língua natural, de forma que a palavra "quebrada" elucida algo que não está inteiro, no contexto da língua natural; e, remete a um número decimal, quando usada no contexto matemático. Aqui fica evidente a influência da forma de vida dos sujeitos que praticam o uso da linguagem. Os sujeitos desse episódio conhecem as regras dos jogos de linguagem que ali ocorrem.

Também, ao procurar elucidar a relação entre o domínio e o contradomínio de uma função o A11 se utiliza de linguagem natural para representar algo matemático. A expressão "é daqui que leva para lá" possui significado matemático, uma vez que faz alusão à relação existente entre domínio e contradomínio. Notamos que ambos os alunos do Episódio 2 estão inseridos tanto no jogo de linguagem da língua natural quanto no jogo de linguagem da linguagem matemática porque eles parecem se entender no diálogo produzido. Entendemos, alicerçados nas asserções de Wittgenstein (2012), que há semelhança de família nesses dois jogos de linguagem porque a utilização da expressão em destaque faz com que o discurso venha carregado de significado.

Neste caso, são as semelhanças de família entre os jogos de linguagem que garantem o entendimento das expressões da língua natural em um contexto matemático, atribuindo-lhe significado, conforme afirma Wittgenstein (2012) a respeito de linguagens e seus significados em cada uso. A expressão "é daqui que leva para lá" ao ser utilizada nesse contexto de aula, ganha um significado matemático. Neste uso, essa expressão elucida a relação ente domínio e imagem. 
Em outro grupo, os alunos, ao tentarem escrever o conjunto que representa o domínio, o contradomínio e a imagem da função, tiveram percalços na definição dos conjuntos citados. O Episódio 3 ilustra esse fato.

\section{Episódio 3}

A22: esse é o domínio? E essa é a imagem? qual a diferença de contradomínio e imagem?

A12: a imagem são os elementos que você pode pegar do contradomínio, a imagem são os elementos específicos, essa é a imagem: todo o conjunto.

A22: então a imagem são todos os reais?

A12: o contradomínio são os reais e a imagem é esse conjunto aqui, daí o domínio pode ser considerado os inteiros positivos mais o zero ou os naturais...

$S$ : a reta do $x$ é o domínio, do y é o contradomínio e a imagem vai ser os pares ordenados.

A12: os pontos específicos.

Identificamos que ao procurar uma definição de cada conjunto os alunos recorrem a expressões do tipo: "pegar do contradomínio", "a reta do x", "a do y" para evocar ideias matemáticas. A expressão "pegar do contradomínio" refere-se à ideia de selecionar elementos no conjunto do contradomínio pertencentes à da imagem da função. Quando o aluno diz "a reta do y" e "a reta do x", parece se referir ao eixo das ordenadas e ao eixo das abscissas, respectivamente. Tais expressões possuem significado no contexto do jogo de linguagem da matemática, muito embora não tenham sido pronunciadas segundo o rigor matemático. Essas expressões vêm, portanto, imbricadas de significado e, nesse sentido, podemos considerar que elas carregam as regras do jogo de linguagem da matemática.

Como os alunos estão inseridos nesse jogo de linguagem, e conhecem as regras que regem tal jogo, comunicam־se utilizando expressões que fazem parte do jogo e que nele possuem significado. Talvez, em um outro contexto, em um outro jogo de linguagem, essas expressões poderiam ter qualquer, ou nenhum, significado. 
Com relação à atribuição de significado, enquanto a turma realizava uma discussão acerca das respostas que consideraram como solução para a atividade, ocorreram divergências com relação à palavra "figura":

\section{Episódio 4}

P: qual figura representa melhor os pontos distribuídos no gráfico? Qual é o problema com essa pergunta?

A12: a gente colocou triângulo.

A13: eu escrevi reta...

A12: se for ver a figura que forma é um triângulo...

S: é, essa palavra figura que ficou meio estranho.

A13: eu coloquei reta, mas reta não é uma figura...

A21: é, reta é uma reta.

A11: mas podia ser tanta coisa, como não pediu para traçar uma reta, podia ser só pontinhos...

Nesse episódio a palavra figura ganhou diferentes interpretações. Para alguns alunos, por causa do formato da pergunta, a figura solicitada deveria ser um triângulo; para outros, uma reta, ou ainda, outra coisa, já que não fora solicitado que fosse realizada alguma ligação entre os pontos na malha quadriculada. Concluímos então que a palavra figura não gerou semelhança de família devido à falta de atribuição de um significado pelos alunos no jogo de linguagem da matemática e da língua materna suscitados.

Para o desenvolvimento da atividade "Horário de Verão" a turma recebeu uma tabela ${ }^{8}$ contendo a duração do dia do nascer ao ocaso do sol. A partir de tais dados deveriam obter uma data mais apropriada para o início e para o término do horário de verão.

Enquanto os alunos discutiam sobre essa problemática a professora indagou uma das duplas com relação às conclusões que haviam chegado,

\footnotetext{
${ }^{8}$ Essa tabela encontra-se no artigo: ALMEIDA, L.M.W.de; BRITO, D. dos S. Modelagem Matemática na sala de aula: algumas implicações para o ensino e aprendizagem da matemática. In: XI CIAEM Conferência Interamericana de Educação Matemática. Blumenau - SC, 2003.
} 
perguntando se a função que obtiveram poderia se configurar como modelo que descreve a situação estudada (Episódio 5).

\section{Episódio 5}

P: que conclusão vocês chegaram?

A11: que vai ser uma função seno. Primeiro a gente pensou numa parábola, numa parábola crescente...

P: como assim uma parábola crescente?

A21: como assim se ela vai para os dois lados?

A11: então não. Acho que não pode ser uma parábola.

$P$ : com uma concavidade para cima, que você tem uma parte crescente até o vértice e do vértice em diante ela é decrescente, ok? E por que que não deu?

A11: esse valor aqui vai decrescer de novo...

$P$ : vai voltar no início...

A11: vai ter um período... função seno...

P: por que não daria para ser várias parábolas grudadinhas? porque isso aqui varia um ano, né? E o janeiro não poderia emendar aqui? Não sei, tô perguntando...

A21: não dá bem certinho... como é que ela vai se encontrar aqui?

Neste episódio reconhecemos que a professora recorre a termos como "grudadinha", "emendar", que fazem parte do jogo de linguagem da língua natural, para explicitar o fato de que, se o problema fosse descrito por uma função que tem intervalos de crescimento e de decrescimento, os dados, não necessariamente, têm de ser traduzidos em termos de uma função trigonométrica. Eles poderiam ser representados por mais de uma função quadrática, representadas graficamente por parábolas que se seguem imediatamente uma ao lado da outra.

$\mathrm{Na}$ gramática presente nesse uso, as palavras "grudadinhas" e "emendar" contém significado com referência a algo matemático e respeitam algumas regras. Por outro lado, quando o A11 se refere à parábola como "crescente", as regras que regem o jogo de linguagem da linguagem 
matemática não são obedecidas, já que matematicamente uma parábola não se classifica como crescente ou decrescente.

Mesmo assim, os termos utilizados pela professora traz à tona uma semelhança de família entre o jogo de linguagem da língua natural com a da linguagem matemática. Assim como Wittgenstein (2012) nos traz que os jogos de carta, de tabuleiro, de bola carregam como semelhança o caráter competitivo de se ganhar ou perder, os dois jogos identificados no Episódio 5 carregam como semelhança a noção de algo muito próximo a outro, nas palavras "grudadinha" e "emendar". A primeira elucida o conceito matemático de uma função representada por parábolas seguidas imediatamente e a palavra "emendar" faz alusão a uma função com períodos.

Cabe ressaltar que essas semelhanças de família são garantidas pelo fato de que os alunos desse episódio fazem parte da mesma forma de vida, ou seja, os jogadores do jogo de linguagem representado conhecem as regras que o regem. Em outro uso, em outro contexto, dizer que duas parábolas estão "grudadas" poderia não carregar o mesmo significado, bem como se os indivíduos não soubessem o que é uma parábola, ou atribuísse outro significado a esse termo.

O Episódio 6 retrata o momento em que todos os grupos debatem, no coletivo, sobre a representação matemática para o problema em estudo.

\section{Episódio 6}

A13: Você pode observar que num período ele começa a... ele vai crescendo e daí ele chega num ponto e decresce, daí ele começa a crescer de novo.

$S:$ tem um período de máximo e de mínimo...e entre esse período tem o que?

A14: ponto médio?

A13: dia mais longo?

S: entre o período de máximo e de mínimo? Se pensar numa função? O que vai dar? A22: ponto de inflexão?

S: ponto de inflexão!

$P$ : o que é um ponto de inflexão? 
A22: ponto de inflexão no caso seria onde a minha função começa a mudar.

P: muda o que?

A23: o formato.

A11: o gráfico.

A22: o comportamento.

A13: era crescente, passa a ser decrescente.

S: pode ser uma aplicação da derivada...

A12: o ponto da reta tangente...

A22: ele cai até aqui depois começa a subir de novo.

Ao serem questionados sobre o que era um ponto de inflexão, conceito matemático que surgiu das observações realizadas em relação ao comportamento da função que focalizava o problema em estudo, os alunos utilizam־se da linguagem natural como forma de elucidar o que entendem como sendo este conceito. As expressões: "a função começa a mudar", "o formato", "o gráfico", "o comportamento", "era crescente, passa a ser decrescente" e "o ponto da reta tangente" são diversos usos da linguagem, que neste contexto procuram assumir o mesmo significado, ou seja, procuram definir o que os alunos entendem por ponto de inflexão.

Essas expressões, presentes no Episódio 6, fazem parte de dois jogos de linguagem identificados nos discursos manifestos durante a realização da atividade de modelagem: o jogo de linguagem da linguagem matemática e o jogo de linguagem da língua natural; e, elas carregam semelhanças de família já que são ditas em um contexto (uma forma de vida) que permite que sejam usadas para fazer compreender algo matemático.

No decorrer da atividade os grupos chegaram a uma função trigonométrica como modelo matemático para o problema em estudo (uma função seno). Entretanto, ocorreram dificuldades com relação ao entendimento da lei geral dessa função e a influência de seus parâmetros. $\mathrm{O}$ Episódio 7 descreve o momento em que todos os grupos se envolvem com a interpretação da influência de um dos parâmetros da função seno: 


\section{Episódio 7}

$P:$ e mais alguma coisa que faz?

Alunos: ela desloca....

P: desloca?

A12: no eixo vertical.

P: o que que é o eixo y? que tipo de deslocamento é esse?

A13: vertical.

$P$ : vertical. Vamos ver como é que funciona, se eu colocar um, a minha função vai para cima ou vai para baixo? No a? o que aconteceu?

Alunos: subiu.

$P:$ quantas unidades?

A23: uma unidade.

P: então, o a se for positivo desloca... para cima, se o a for negativo...para baixo? Será? Bota lá no menos um pra ver.

(...)

P: então, se colocar o a no menos um deslocou uma unidade...

Alunos: para baixo.

P: para baixo. Então se eu quiser deslocar três unidades para cima?

A21: o a tem que ser três.

P: hum? O a tem que ser três. E se eu quiser deslocar cinco unidades para baixo? A21: a igual a menos cinco.

Neste episódio identificamos a presença do jogo de linguagem da língua natural no discurso da professora e dos alunos ao tentar descrever o comportamento da função, propondo a alteração de um dos parâmetros ${ }^{9}$, denominado, neste caso, de a. Além disso, encontramos presente o jogo de linguagem matemático, quando falam alguns conceitos matemáticos na análise e interpretação gráfica que realizam acerca da função seno.

Na elaboração dos discursos, por exemplo, nas expressões "bota lá no menos um para ver" e "se colocar no um", que fazem referência à atribuição do valor um negativo e um positivo para o parâmetro a na função seno e da

\footnotetext{
${ }^{9}$ Essa análise dos parâmetros, em particular do parâmetro a, foi realizada utilizando-se de um recurso tecnológico, a saber, o software Geogebra.
} 
análise da influência destas atribuições na representação gráfica, encontramos semelhanças de família entre o jogo de linguagem da língua natural com o jogo de linguagem da linguagem matemática. A professora ao utilizar tais expressões, que fazem parte da língua natural, procura significar algo matemático.

Ainda neste episódio, evidenciamos que a professora ao solicitar que os alunos atribuíssem valores a fim de notarem a influência dos parâmetros da função seno, fez suscitar semelhanças de família entre o jogo de linguagem da língua natural e o jogo de linguagem da matemática. Essa atitude pode ter favorecido atribuição de significado, já que os conceitos matemáticos expostos verbalmente se articulavam com as análises realizadas pelos alunos sob a forma de representação gráfica da função seno.

Além disso, os alunos, sendo pertencentes a mesma forma de vida, conheciam as regras de todos os jogos envolvidos.

Os discursos presentes em todos os episódios que subsidiaram nossas interpretações são regidos por regras que compõem os jogos identificados, e tais regras são conhecidas pelos integrantes dos jogos. Os alunos, imersos em um contexto de Modelagem Matemática, se comunicam de forma a trazer à tona suas formas de vida ao passo que buscam resolver os problemas em estudo.

\section{Considerações finais}

As linguagens manifestas nas interações de uma aula que concentra o estudo de atividades de modelagem matemática podem ser diversas, porém, alunos e professor ao se comunicarem utilizam com maior frequência a linguagem natural, que é a linguagem utilizada no cotidiano, e a linguagem matemática, que é a linguagem acadêmica, que possui rigor científico e, desta utilização, que preserva as características dessas duas linguagens citadas, surgem os jogos de linguagens. Ao jogar estes jogos, professores e 
alunos se fazem compreender, uma vez que estes jogos guardam semelhanças de família entre eles.

Um dos aspectos evidenciados neste estudo é que quando os alunos que fazem parte de um ambiente (forma de vida) de uma sala de aula na qual ocorrem atividades de modelagem matemática, se comunicam, os discursos que são elaborados para se expressarem são formados por termos próprios da linguagem natural, que é a linguagem que eles utilizam para comunicarse no dia a dia, e por termos próprios da linguagem matemática, que é o contexto no qual os jogos de linguagem se formam.

Essa variação de linguagens se justifica, em partes, por atividades de modelagem envolverem naturalmente dois contextos distintos: o contexto real, no qual se assenta a problemática evidenciada para estudo e; a matemática, ciência sob a qual se busca compreender tal problemática e da qual se utiliza procedimentos e conceitos que favorecem tal compreensão.

Ao jogarem com a linguagem em uma ambiente de modelagem, professor e alunos deixam transparecer que conhecem as regras que regem os jogos de linguagem suscitados e assim, termos e expressões proferidas são compreendidas no processo de comunicação.

As análises também indicaram que os jogos de linguagem presentes nas falas dos envolvidos com as atividades de modelagem matemática guardam semelhanças de família entre si, de forma que os discursos elaborados apresentam termos que carregam parentescos entre os jogos de linguagem citados. Por exemplo, ao se referirem a objetos matemáticos, alunos e professora fizeram uso de termos da língua natural e suas falas eram entendidas, indicando que os jogadores destes jogos conheciam as regras regidas por tais jogos e, portanto, conseguiam atribuir significado ao que era dito em cada jogo.

Podemos concluir que no encaminhamento de uma atividade de modelagem matemática, professores e alunos se encontram imersos no jogo de linguagem da linguagem matemática, mas se utilizam de expressões da linguagem natural para comunicar as ideias matemáticas. Tais expressões, 
nos jogos de linguagem em que são enunciadas, ganham significado, pois de um modo ou de outro carregam semelhanças de família.

\section{Referências}

ALMEIDA, L. M. W. de; DIAS, M. R. Modelagem Matemática em cursos de formação de professores. In: BARBOSA, J. C.; CALDEIRA, A. D.; ARAÚJO, J de L. (Org.) Modelagem Matemática na Educação Matemática Brasileira: pesquisas e práticas educacionais; Recife: SBEM, 2007.

ALMEIDA, L. M. W. de; TORTOLA, E. Modelagem Matemática no Ensino Fundamental: a linguagem de alunos como foco de análise. JIEEM - Jornal Internacional de Estudos em Educação Matemática. v. 7(1), p. 111-142, 2014.

CONDÉ, M. L. L. Wittgenstein linguagem e mundo. São Paulo: Annablume, 1998.

VEIGA-NETO, A.; LOPES, M. C. Identidade, cultura e semelhanças de família: as contribuições da virada linguística. In: BIZARRO, R. (Org.). Eu e o outro: estudos multidisciplinares sobre identidade(s), diversidade(s) e práticas interculturais. Porto: Areal, 2007.

VERONEZ, M. R. D. As funções dos signos em atividades de modelagem matemática. 2013. 176p. Tese de Doutorado (Pós-Graduação em Ensino de Ciências e Educação Matemática) - Universidade Estadual de Londrina, Londrina, 2013.

VERONEZ, M. R. D.; ESTEVAM, E. J. G. Linguagens manifestadas por (futuros) professores que ensinam matemática em tarefas de multiplicação e divisão. Revista Eletrônica de Educação, v. 9, n. 3, p. 304-320, 2015.

VILELA, D. S. MENDES, J. R. A linguagem como eixo da pesquisa em educação matemática: contribuições da filosofia e dos estudos do discurso. Zetetiké, FE/Unicamp, Campinas, v. 19, n. 36, jul./dez. 2011.

WITTGENSTEIN, L.; Investigações Filosóficas (tradução de Marcos G. Montagnoli); 7 ed.; Petrópolis, RJ: Vozes; Bragança Paulista, SP: Editora Universitária São Francisco, 2012. 